\title{
Long-term follow-up after primary complete repair of common arterial trunk with homograft: A 40-year experience
}

\author{
Hunaid A. Vohra, FRCS (CTh), ${ }^{a}$ Robert N. Whistance, MRCS, ${ }^{\mathrm{a}}$ Alicia X. Chia, MB, ChB, ${ }^{\mathrm{a}}$

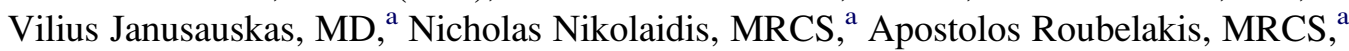 \\ Gruschen Veldtman, MRCP, ${ }^{\mathrm{b}}$ Kevin Roman, MRCP, ${ }^{\mathrm{b}}$ Joseph J. Vettukattil, MRCP, ${ }^{\mathrm{b}}$ \\ James Gnanapragasam, MRCP, ${ }^{\mathrm{b}}$ Anthony P. Salmon, FRCP, ${ }^{\mathrm{b}}$ James L. Monro, FRCS, ${ }^{\mathrm{a}}$ and \\ Marcus P. Haw, FRCS (CTh) ${ }^{\mathrm{a}}$
}

Background: We sought to determine the long-term performance of homograft and truncal valve after complete repair of common arterial trunk.

\begin{abstract}
Methods: From January 1964 to June 2008, 32 patients (median age, 14 days; range, 5 days to 2.5 years) underwent primary homograft repair of common arterial trunk. Twenty-four $(75 \%)$ were neonates. The homograft used in the right ventricular outflow tract was aortic in 24 patients and pulmonary in 8 patients (mean diameter, $15.8 \pm$ $3.5 \mathrm{~mm}$; median diameter, $16 \mathrm{~mm}$ [range, $8-24 \mathrm{~mm}$ ]). The median follow-up was 24.5 years (range, 5.6 months to 43.5 years).
\end{abstract}

Results: There were 3 hospital deaths and 1 late death. The actuarial survival at 30 years was $83.1 \% \pm 6.6 \%$. Of the 28 survivors, 25 reoperations were performed in $19(76 \%)$ patients. The mean and median times to homograft reoperation were $11.5 \pm 7.4$ and 12.1 years (range, $1.0-26.1$ years), respectively. Overall freedom from homograft reoperation after 10,20 , and 30 years was $68.4 \% \pm 8.7 \%, 37.4 \% \pm 9.5 \%$, and $26.7 \% \pm 9.3 \%$, respectively. Twelve patients retained the original homografts at a median follow-up of 16.4 years (range, $0-30.2$ years). Six underwent a truncal valve replacement with a mechanical prosthesis at a median of 10.5 years (range, 3.4-22 years) after truncus repair. Freedom from truncal valve replacement at 10 and 30 years was $93.1 \% \pm 4.7 \%$ and $81.8 \% \pm 8.9 \%$, respectively. In the 22 surviving patients who did not undergo truncal valve replacement, the peak truncal valve gradient was $8.9 \pm 8.3 \mathrm{~mm} \mathrm{Hg}$ at a median follow-up of 24.5 years (range, 5.6 months to 32.9 years). At the last follow-up, $27(96.4 \%)$ patients had good left ventricular function, and 24 patients $(85.7 \%)$ were New York Heart Association class I.

Conclusions: Oversizing the homograft at the time of the initial repair can lead to a homograft lasting more than 12 years. During long-term follow-up, $20 \%$ of patients require truncal valve replacement. (J Thorac Cardiovasc Surg 2010;140:325-9)

Common arterial trunk (CAT) is a rare abnormality that accounts for less than $3 \%$ of congenital cardiac disease..$^{1-3}$ Without surgical intervention, the mortality of patients with CAT approaches $80 \%$ at 1 year. ${ }^{2,3}$ Reconstruction of the right ventricular outflow tract (RVOT) is necessary to establish a separate pulmonary circulation and is one of the most challenging aspects of surgical intervention in patients with CAT. A range of RVOT reconstruction grafts are available, but at present, homografts are considered the gold standard. ${ }^{4}$ Homografts offer good durability, low rates of stenosis, and long-term freedom from reoperation. ${ }^{4-8}$

\footnotetext{
From the Departments of Cardiothoracic Surgery ${ }^{\mathrm{a}}$ and Paediatric Cardiology, ${ }^{\mathrm{b}}$ Southampton University Hospital Trust, Southampton, United Kingdom.

Disclosures: None.

Received for publication May 1, 2009; revisions received Nov 27, 2009; accepted for publication Dec 20, 2009; available ahead of print April 29, 2010.

Address for reprints: Marcus P. Haw, FRCS (CTh), Department of Cardiothoracic Surgery, Wessex Cardiac Unit, Southampton University Hospital Trust, Southampton SO166YD, United Kingdom (E-mail: Marcus.Haw@suht.swest.nhs.uk). $0022-5223 / \$ 36.00$

Copyright (c) 2010 by The American Association for Thoracic Surgery doi:10.1016/j.jtcvs.2009.12.052
}

Aortic or pulmonary homografts can be used for RVOT reconstruction, and it is arguable which is superior. ${ }^{9,10}$ Recently, valved xenografts, such as Contegra (Medtronic, Inc, Minneapolis, Minn), have come to the fore mainly as a result of their off-the-shelf availability and broad range of sizes. ${ }^{11}$ Doubts remain over the long-term durability of these implants, although in the medium term Contegra conduits appear comparable with homografts. ${ }^{11,12}$

Outcomes after surgical intervention for CAT have traditionally been measured in terms of short- and long-term survival. Indeed, most deaths occur early in the postoperative period or are related to later reintervention. ${ }^{13,14}$ Actuarial survival has been reported as $90 \%$ at 5 years, $85 \%$ at 10 years, and $83 \%$ at 15 years in those surviving discharge from the hospital, and this is broadly consistent with other long-term studies. ${ }^{14-16}$ With an increase in mortality being linked to revision surgery, the time to reintervention for graft dysfunction is an important outcome measure in patients with CAT. The principle factor associated with a shorter time to conduit replacement is smaller conduit size at primary intervention. ${ }^{14,17}$ Other common indications for reintervention include homograft 


$$
\begin{aligned}
& \text { Abbreviations and Acronyms } \\
& \text { CAT }=\text { common arterial trunk } \\
& \text { MPA }=\text { main pulmonary artery } \\
& \text { NYHA }=\text { New York Heart Association } \\
& \text { PA }=\text { pulmonary artery } \\
& \text { RA }=\text { right atrium } \\
& \text { RVOT }=\text { right ventricular outflow tract }
\end{aligned}
$$

stenosis or calcification, truncal valve regurgitation, and infective endocarditis. Functional outcomes are also of clinical importance and include the presence of congestive cardiac failure and the effect of symptoms on health-related quality of life. In this study we report our 40-year experience of CAT repair with homografts. To our knowledge, this is the longest follow-up reported.

\section{MATERIALS AND METHODS}

Patients who had undergone primary repair of CAT with a homograft (aortic or pulmonary) between January 1964 and June 2008 were included in this study. Data (including follow-up) were collected from computerized databases (HeartSuite; Systeria Ltd, Glasgow, United Kingdom) and patient notes, retrospectively. Patient consent was waived by the institutional board. Thirty-two patients were identified with a median age of 14 days (range, 5 days to 2.5 years; Table 1 ). Of these, the majority underwent primary repair as neonates in the first month of life $(n=24,75 \%)$. The 8 remaining patients underwent repair beyond 1 month of life (1-3 months, $n=3 ; 3-6$ months, $\mathrm{n}=3 ;>1$ year, $\mathrm{n}=2$ ). The reasons for late primary repair were delayed referral $(n=7)$ and severe noncardiac disease necessitating treatment before CAT repair $(n=1)$.

Several CAT anatomic variants were seen in our series, and these were classified according to the standard system. ${ }^{18}$ The majority of patients $(\mathrm{n}=24,75 \%)$ had A1 CAT, with a single pulmonary trunk arising from the common trunk. Six (18.7\%) patients had A2 CAT, with separate origins of the left and right branch pulmonary arteries (PAs) from the lateral aspects of the common trunk. The remaining $2(6.2 \%)$ patients were classified as having A4 CAT, with an associated interrupted aortic arch. Surgical intervention typically involved median sternotomy, cardiopulmonary bypass with moderate hypothermia, and crystalloid cardioplegic arrest. The common trunk and truncal valve were committed to the left ventricle with closure of any associated ventricular septal defect. The RVOT was subsequently reconstructed with either an aortic $(n=25,78.1 \%)$ or pulmonary $(\mathrm{n}=7,21.9 \%)$ cryopreserved homograft. The mean diameter of the homografts was $15.8 \pm 3.5 \mathrm{~mm}$, and the median diameter was $16 \mathrm{~mm}$ (range, 8-24 mm). In the 24 neonates the median size of the homografts used was $15 \mathrm{~mm}$, with a range between 8 and $20 \mathrm{~mm}$. Concomitant procedures were performed in several cases and included ventricular septal defect closure $(\mathrm{n}=6)$, aortic root replacement for truncal valve regurgitation $(\mathrm{n}=1)$, and repair of an interrupted aortic arch $(\mathrm{n}=2)$. Indications for homograft reoperation included pulmonary regurgitation, stenosis with symptoms, or both; asymptomatic severe pulmonary regurgitation; and pulmonary stenosis with a gradient of greater than $50 \mathrm{~mm} \mathrm{Hg}$. Follow-up was complete for all patients and included assessment of functional status (New York Heart Association [NYHA] classification).

\section{Operative Details}

Surgical intervention was performed through a median sternotomy. Cardiopulmonary bypass was established with bicaval and distal ascending aortic cannulation. The patient was cooled to $28^{\circ} \mathrm{C}$. Deep hypothermic circulatory arrest was only used if intervention on the aortic arch was performed. The patient was cooled to $18^{\circ} \mathrm{C}$ in these cases. The ductus arteriosus was ligated and divided if patent. Snares were placed around the right and left PAs and cavae, and the heart was arrested with intermittent antegrade cold blood cardioplegia. Topical cooling was applied. The right atrium (RA) was opened parallel to the atrioventricular groove, and a vent was placed through a patent foramen ovale (created if necessary). The main pulmonary artery (MPA) was divided from the aorta, and the incision in the truncus was continued to the right in a horizontal fashion above the truncal valve. The truncal valve was then inspected, and the appropriate procedure was performed, if required (see below). The aorta was then closed with continuous 6-0 Prolene sutures (Ethicon, Inc, Somerville, NJ). A bovine pericardial patch on the aorta was applied only if required. Cardioplegia was given, which also tests the truncal valve competence. The ventricular septal defect was then inspected through the RA and, if present, was closed with an autologous pericardial patch with continuous 5-0 Prolene sutures. Next the bifurcation of the MPA was inspected. If small/stenosed, the right PA, left PA, or both was augmented with an autologous pericardial patch. We used antibiotic-sterilized homografts until April 2001 and cryopreserved homografts since then.

The homograft was then trimmed and anastomosed to the MPA bifurcation with continuous 6-0 Prolene sutures. The proximal end of the homograft was then anastomosed to a right ventriculotomy with continuous 5-0 Prolene sutures. The RA was then closed. Deairing was performed through the aortic root, and the crossclamp was removed. Standard cardiac surgery steps were then followed. To fit a 16-mm or larger homograft onto a newborn heart, we anastomosed the homograft to the RVOT between the truncal valve and the left anterior descending coronary artery. The anastomosis is fashioned so that the homograft arises from the right ventricle at an angle of $90^{\circ}$. In this way, instead of heading straight toward the PA bifurcation, the homograft is directed toward the left lung. The left pleura is then opened, enabling the homograft to swing over into the medial part of the left pleural cavity, and is then turned back onto the PA bifurcation. Distally, the incision/anastomosis is extended onto the left PA in a beveled fashion. We have not had any problems with this oversizing.

\section{Statistical Analyses}

Data are expressed as frequencies, means \pm standard deviations, or medians with ranges, as appropriate. Survival, time to replacement of the homograft, and time to aortic/truncal valve replacement are expressed as Kaplan-Meier curves. SPSS software (15.1.2 for Windows; SPSS, Inc, Chicago, Ill) was used.

\section{RESULTS}

There were 3 inpatient deaths after primary CAT repair. The last death occurred in 1989. One patient had severe aortic/truncal valve regurgitation, whereas 2 patients experienced perioperative cardiac arrest. Of the latter, one had severe hypoxic cerebral damage, and the other had recurrent pulmonary hypertensive crises and low cardiac output. In our series there was 1 late death with 28 long-term survivors. Follow-up among all surviving patients was complete, with a median follow-up time of 24.5 years (range, 5.6 months to 43.5 years). The actuarial survival at 30 years was $83.1 \% \pm$ $6.6 \%$ (Figure 1).

Reoperations resulted in 25 repeat procedures in 19 $(76 \%)$ patients. The majority of patients underwent a single revision $(\mathrm{n}=13)$; however, some patients required further intervention (double revision, $\mathrm{n}=3$; triple revision, 
TABLE 1. Patients' characteristics

\begin{tabular}{lc}
\hline & No. $(\mathbf{n}=\mathbf{3 2})$ \\
\hline Median age at time of operation & $14 \mathrm{~d}($ range, $5 \mathrm{~d}$ to $2.5 \mathrm{y})$ \\
Sex $(\%)$ & $13(40.6)$ \\
Male & $19(59.3)$ \\
Female & \\
CAT anatomic classification $(\%)$ & $24(75)$ \\
A1 & $6(18.7)$ \\
A2 & $0(0.0)$ \\
A3 & $2(6.2)$ \\
A4 & \\
Type of homograft at primary operation $(\%)$ & $25(78.1)$ \\
Aortic & $7(21.9)$ \\
Pulmonary & $3(9.3)$ \\
Mortality $(\%)$ & $14(82.3)$ \\
Indication for homograft reoperation $(\% ; n=17)$ & $2(11.8)$ \\
Stenosis & $1(5.9)$ \\
Infective endocarditis & \\
Thrombosis &
\end{tabular}

$\mathrm{n}=2$ ). The mean and median times to homograft reoperation were $11.5 \pm 7.4$ and 12.1 years (range, $1.0-26.1$ years), respectively. The main indication for revision was homograft stenosis $(n=14)$, although other complications occurred. We did not find any difference in terms of durability of the pulmonary and aortic homografts. The aortic homografts did not calcify and stenose earlier. Homograft replacement was the most common reintervention $(n=16$ in 12 patients), with 1 patient undergoing homograft repair. In our series freedom from homograft reoperation was $68.4 \% \pm 8.7 \%$ at 10 years, $37.4 \% \pm 9.5 \%$ at 20 years, and $26.7 \% \pm 9.3 \%$ at 30 years (Figure 2). Indeed, 12 patients retained their original homografts at a median follow-up of 16.4 years (range, 0-30.2 years). The peak RVOT gradient in these patients at last follow-up was $38.9 \pm 5.3 \mathrm{~mm} \mathrm{Hg}$. One patient required balloon dilatation of the origins of the right and left PAs, 1 patient required

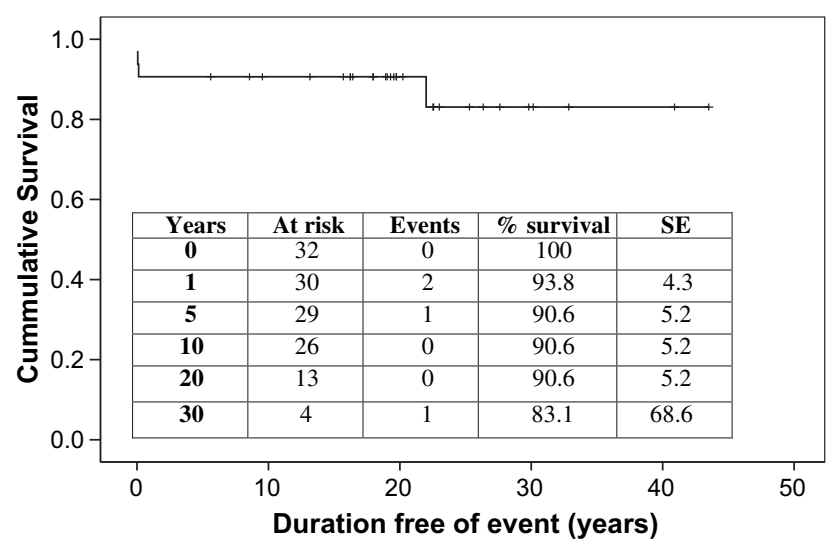

FIGURE 1. Kaplan-Meier estimate of survival in all patients: number of patients at risk, percentage of patients surviving, and standard error ( $S E)$ as a percentage are shown.

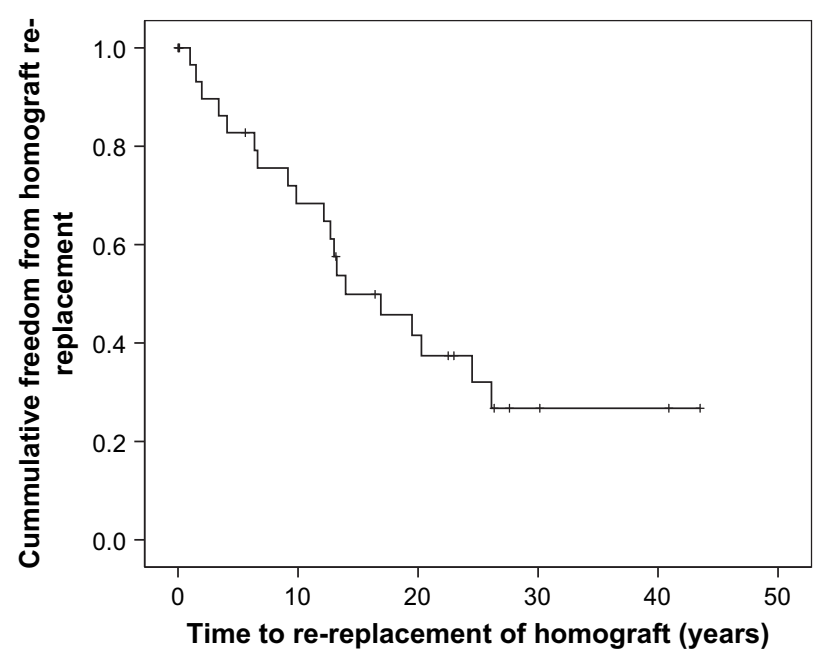

\begin{tabular}{|c|c|c|c|c|}
\hline Years & At risk & Events & $\begin{array}{c}\text { \% free of re- } \\
\text { replacement }\end{array}$ & SE \\
\hline $\mathbf{0}$ & 32 & 0 & 100 & \\
\hline $\mathbf{1}$ & 28 & 1 & 96.6 & 3.4 \\
\hline $\mathbf{5}$ & 24 & 4 & 82.8 & 7.0 \\
\hline $\mathbf{1 0}$ & 19 & 4 & 68.4 & 8.7 \\
\hline $\mathbf{1 5}$ & 13 & 5 & 49.9 & 9.5 \\
\hline $\mathbf{2 0}$ & 9 & 3 & 37.4 & 9.5 \\
\hline $\mathbf{3 0}$ & 2 & 2 & 26.7 & 9.3 \\
\hline
\end{tabular}

FIGURE 2. Kaplan-Meier estimate of freedom from homograft replacement: number of patients at risk, percentage of patients free from homograft replacement, and standard error $(S E)$ as a percentage are shown.

ventricular tachycardia ablation, and 1 patient required accessory pathway ablation, occurring 22,11 , and 9.5 years after the original operation, respectively.

Six reoperations were performed during follow-up in 5 patients for severe truncal/aortic valve regurgitation. Of these, 3 underwent truncal valve replacement alone, 1 received an aortic root replacement, and 1 underwent an aortic valve replacement followed later by an aortic root replacement. The median time to truncal valve replacement was 10.5 years (range, 3.4-22.0 years) after truncus repair, whereas freedom from truncal valve replacement was $93.1 \% \pm 4.7 \%$ at 10 years and $81.8 \% \pm 8.9 \%$ at 30 years among all participants (Figure 3 ). In the 22 surviving patients who did not undergo truncal valve replacement, the peak aortic truncal/ aortic valve gradient was $8.9 \pm 8.3 \mathrm{~mm} \mathrm{Hg}$ at a median follow-up of 24.5 years (range, 5.6-32.9 years). Truncal/ aortic valve regurgitation in the 20 patients was minimal (nil/trace, $\mathrm{n}=18$; mild, $\mathrm{n}=4$ ). At final follow-up, 27 $(96.4 \%)$ of the surviving patients had good left ventricular function on echocardiographic analysis. At this stage, the majority of patients were in NYHA class I $(n=24$, $85.7 \%$ ). Four $(10.7 \%)$ patients had slight limitation of physical activity (NYHA class II), whereas only $1(3.6 \%)$ patient was in NYHA class III. Complications occurred in 4 patients by final follow-up and included cerebrovascular accident $(\mathrm{n}=1)$, recurrent chest infections $(\mathrm{n}=1)$, ventricular tachycardia requiring ablation therapy $(\mathrm{n}=1)$, and ablation of an accessory pathway $(\mathrm{n}=1)$. 


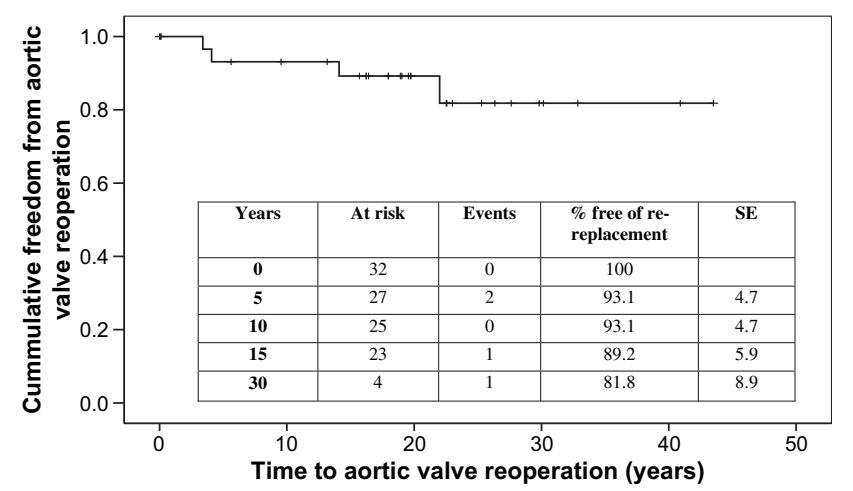

FIGURE 3. Kaplan-Meier estimate of freedom from truncal valve operations: number of patients at risk, percentage of patients free from truncal valve replacement, and standard error $(S E)$ as a percentage are shown.

\section{DISCUSSION}

Long-term studies of the clinical and functional outcomes in CAT repair are needed to inform decision making when planning surgical intervention. Early and late mortality, freedom from RVOT graft reintervention, and the functional performance of the truncal valve are all important factors that need to be taken into account. Reconstruction of the RVOT is a key part of the procedure, with a range of grafts available, including pulmonary or aortic homografts, porcine xenografts, and valved bovine jugular vein (Contegra). This retrospective study looked at 40 years of experience of treating CAT with homograft reconstruction of the RVOT.

Surgical intervention in patients with CAT is often challenging, with a significant mortality if prompt treatment is not instigated. In our sample of 32 patients, there were 3 $(9.3 \%)$ early inpatient deaths and $24(90.7 \%)$ long-term survivors. This is broadly in agreement with other studies, which have demonstrated similar early mortality rates, with the majority of deaths occurring in the early postoperative period. ${ }^{14,16,19}$ The actuarial survival in our study was $83.1 \% \pm 6.6 \%$ at 30 years, indicating that the majority of patients with CAT survive long term. Similar but less efficacious results have been reported in the literature, with one study demonstrating an $83 \%$ actuarial survival at 15 years postoperatively. ${ }^{13}$ Other studies with shorter follow-up periods have reported actuarial survival figures of $93 \%$ at 6 years and $96 \%$ at 3 years. ${ }^{14,20}$ Our excellent long-term survival figures could be attributed to a relatively low incidence of complications, good hemodynamics, and the need for infrequent reintervention in the CAT patient population.

At the time of primary CAT surgery, in the first few months of life, the small size of the heart necessitates the use of a comparably small RVOT reconstruction graft. With advancing age, patients are at risk of outgrowing their graft, resulting almost inevitably in graft failure and the need for reintervention. Indeed, 10-year freedom from explantation is greater when a larger homograft $(>19 \mathrm{~mm})$ is used at the initial operation. ${ }^{4}$ Other factors also influence the likelihood of early RVOT graft failure and include graft stenosis, calcification, and infective endocarditis. Reoperation for graft failure can be technically difficult and carries with it a significant risk of morbidity and mortality. Increasing the time to graft reintervention is thus an important goal in the management of patients with CAT. In our study comprising a follow-up of up to more than 40 years, 19 (67\%) patients required reintervention for homograft failure, some more than once. Replacement of the homograft was the treatment of choice in most patients. Other studies have demonstrated similar actuarial freedom from reoperation figures over similar follow-up periods. ${ }^{21-23}$ Homografts thus seem to offer good durability with a low incidence of failure when used in patients with CAT. Several studies have compared homografts with Contegra bovine jugular vein grafts for RVOT reconstruction. ${ }^{11,12}$ Freedom from graft dysfunction and reoperation was comparable in these 2 groups up to a maximum follow-up time of 7 years. However, these studies looked at a mixed patient population and not solely patients with CAT over a comparatively short timeframe.

Truncal valve regurgitation is often cited as a predictor of poor outcome after surgical intervention for CAT, especially when associated with an interrupted aortic arch. ${ }^{13,21,24}$ Our policy for first-time surgical intervention is to repair the truncal valves by either tricuspidizing a quadricuspid valve or repair of the bicuspid valve if there is moderateto-severe regurgitation. Truncal valve replacement is also an appropriate management option that can be accomplished with either mechanical prostheses or valved aortic homografts. In our series $1(33 \%)$ of the 3 cases of early mortality was attributed to severe truncal valve regurgitation. Of the 28 long-term survivors, only $5(17.8 \%)$ had truncal valve incompetence, with excellent overall freedom from truncal valve reoperation at both 10 and 30 years. These patients also took a comparatively long time (10.5 years) to require truncal valve replacement. The 6 truncal valve replacements were performed during follow-up after primary repair of CAT. The regurgitation grade at the time of the initial repair was none to mild in these patients. We assessed all these valves for repair first during surgical intervention. However, in this redo setting our threshold for replacement was low for these very dysplastic valves and hence the replacements. Other authors have reported similar freedom from truncal valve reoperation, with a shorter time to reoperation if truncal insufficiency was present before initial repair. ${ }^{13,25}$ Truncal insufficiency and stenosis can be associated with progressive left ventricular dysfunction. In the patients in our study who did not require truncal valve replacement by final follow-up, the vast majority demonstrated good hemodynamics with low truncal gradients and minimal regurgitation across the truncal valve. A reason for this might be appropriate and prompt selection of patients in need of 
truncal valve replacement in our series. However, it is more likely that truncal valves actually perform well and have good long-term hemodynamics in a majority of patients. Indeed, left ventricular function was preserved in most patients, whereas there was a low incidence of physical symptoms of cardiac failure.

This study should be interpreted in light of its limitations. The study is retrospective and contains smaller numbers of patients. However, CAT is an uncommon cardiac anomaly, and case series such as this one from single specialist centers are important for expanding our knowledge of the subject.

This study has looked at the outcomes of using homografts in the primary repair of CAT. We have demonstrated that long-term survival is excellent, and patients can expect roughly 12 years of freedom from reoperation for homograft failure. Reintervention for truncal valve complications is also uncommon among these patients and, if needed, occurs around 10 years from primary repair. The long-term functional outcomes in terms of left ventricular dysfunction and symptoms of cardiac failure are also impressive.

\section{References}

1. Samanek M, Voriskova M. Congenital heart disease among 815,569 children born between 1980 and 1990 and their 15-year survival: a prospective Bohemia survival study. Pediatr Cardiol. 1999;20:411-7.

2. Di Donato RM, Fyfe DA, Puga FJ. Fifteen-year experience with surgical repair of truncus arteriosus. J Thorac Cardiovasc Surg. 1985;89:414-22.

3. Marcelletti C, McGoon DC, Mair DD. The natural history of truncus arteriosus. Circulation. 1976;54:108-11.

4. Boethig D, Goerler H, Westhoff-Bleck M, Ono M, Daiber A, Haverich A, et al. Evaluation of 188 consecutive homografts implanted in the pulmonary position after 20 years. Eur J Cardiothorac Surg. 2007;32:133-42.

5. Tatebe S, Nagakura S, Boyle EM Jr, Duncan BW. Right ventricle to pulmonary artery reconstruction using a valved homograft. Circ J. 2003;67:906-12.

6. Reddy VM, Rajasinghe HA, McElhinney DB, Hanley FL. Performance of right ventricle to pulmonary artery conduits after repair of truncus arteriosus: a comparison of Dacron-housed porcine valves and cryopreserved allografts. Semin Thorac Cardiovasc Surg. 1995; 7:133-8.

7. Lange R, Weipert J, Homann M, Mendler N, Paek SU, Holper K, et al. Performance of allografts and xenografts for right ventricular outflow tract reconstruction. Ann Thorac Surg. 2001;71(suppl):S365-7.

8. Dittrich S, Alexi-Meskishvili VV, Yankah AC, Dahnert I, Meyer R, Hetzer R, et al. Comparison of porcine xenografts and homografts for pulmonary valve replacement in children. Ann Thorac Surg. 2000;70:717-22.
9. Niwaya K, Knott-Craig CJ, Lane MM, Chandrasekaren K, Overholt ED, Elkins RC. Cryopreserved homograft valves in the pulmonary position: risk analysis for intermediate-term failure. J Thorac Cardiovasc Surg. 1999;117:141-6.

10. Fiane AE, Lindberg HL, Seem E, Geiran OR. Homografts for right ventricular outflow tract reconstruction in congenital heart disease. Scand Cardiovasc J. 1997;31:351-6.

11. Sierra J, Christenson JT, Lahlaidi NH, Beghetti M, Kalangos A. Right ventricular outflow tract reconstruction: what conduit to use? Homograft or Contegra? Ann Thorac Surg. 2007;84:606-10.

12. Sinzobahamvya N, Asfour B, Boscheinen M, Photaidis J, Fink C, Schindler E, et al. Compared fate of small-diameter Contegras and homografts in the pulmonary position. Eur J Cardiothorac Surg. 2007;32:209-14.

13. Rajasinghe HA, McElhinney DB, Reddy VM, Mora BN, Hanley FL. Long-term follow up of truncus arteriosus repaired in infancy: a twenty year experience. J Thorac Cardiovasc Surg. 1997;113:869-78.

14. Kalavrouziotis G, Purohit M, Ciotti G, Corno AF, Pozzi M. Truncus arteriosus communis: early and midterm results of early primary repair. Ann Thorac Surg. 2006;82:2200-6.

15. Slavik Z, Keeton BR, Salmon AP, Sutherland GR, Fong LV, Monro JL. Persisten truncus arteriosus operated during infancy: long-term follow-up. Pediatr Cardiol. 1994; 15:112-5.

16. Ullmann MV, Gorenflo M, Sebening C, Ulmer HE, Hagl S. Long-term results after repair of truncus arteriosus communis in neonates and infants. Thorac Cardiovasc Surg. 2003;51:175-9.

17. Meyns B, Jashari R, Gewillig M, Mertens L, Komarek A, Lesaffre E, et al. Factors influencing the survival of cryopreserved homografts. The second homograft performs as well as the first. Eur J Cardiothorac Surg. 2005;28:211-6.

18. Van Praagh R, Van Praagh S. The anatomy of common aorticopulmonary trunk (truncus arteriosus communis) and its embryologic implications. A study of 57 necropsy cases. Am J Cardiol. 1965;16:406-25.

19. Benjacholamas V, Namchaisiri J, Khongphatthanayothin A, Lertsapcharoen P. Bicuspidized pulmonary homograft for truncus arteriosus repair. Asian Cardiovasc Thorac Ann. 2008;16:189-93.

20. Jahangiri M, Zurakowski D, Mayer JE, del Nido PJ, Jonas RA. Repair of the truncal valve and associated interrupted arch in neonates with truncus arteriosus. J Thorac Cardiovasc Surg. 2000;119:508-14.

21. Urban AE, Sinzobahamvya N, Brecher AM, Wetter J, Malorny S. Truncus arteriosus: ten-year experience with homograft repair in neonates and infants. Ann Thorac Surg. 1998;66(suppl):S183-8.

22. Lacour-Gayet F, Serraf A, Komiya T, Sousa-Uva M, Bruniaux J, Touchot A, et al. Truncus arteriosus repair: influence of techniques of right ventricular outflow tract reconstruction. J Thorac Cardiovasc Surg. 1996;111:849-56.

23. Brown JW, Ruzmetov M, Okada Y, Vijay P, Turrentine MW. Truncus arteriosus: outcomes, risk factors, reoperation and management. Eur J Cardiothorac Surg. 2001;20:221-7.

24. Jahangiri M, Zurakowski D, Mayer JE, del Nido PJ, Jonas RA. Repair of trunca valve and associated interrupted aortic arch in neonates with truncus arteriosus. J Thorac Cardiovasc Surg. 2000;119:508-14.

25. McElhinney DB, Rajasinghe HA, Mora BN, Reddy VM, Silverman NH Hanley FL. Reinterventions after repair of common arterial trunk in neonates and young infants. J Am Coll Cardiol. 2000;35:1317-22. 